\title{
Clarice Lispector: La Transgresión Como Acto de Libertad
}

"Crear no es imaginación, es correr el gran riesgo
de poseer la realidad".

(La pasión según G. H.)

"Además de contar los hechos también adivino y lo que adivino aquí escribo, escribana que soy por fatalidad. Yo adivino la realidad."

(La via crucis del cuerpo) 1

La obra de Clarice Lispector nos parece, desde sus inicios, una de las inventivas más renovadoras que se producen en América Hispánica. A partir de su libro de estreno-Perto do coração selvagem (1944)- nuevos caminos se abren para la literatura brasileña, al hacer de la narrativa problematizada una forma de conocimiento. La visión subjetiva del mundo (o intimismo) y el documentarismo, he aquí las líneas maestras de la ficción brasileña, después de 1940. Entre ambas tendencias, siguiendo lo que había sido iniciado en 22, la experimentación de nuevas técnicas configuró nuevos medios de expresión.

El Romanticismo, inaugurando la representación de zonas regionales, marcó una tendencia que se extendió hasta nuestros días, con sensibles ampliaciones y diversificaciones en su espacio textual, manteniendo una línea de tradición (fenómeno común a toda América Hispánica). El Modernismo quiso configurar la vida de la ciudad con nuevas perspectivas, en un globalismo totalizador. La ciudad surge firmada por el afán de modernidad. Desde sus primeros cuentos y novelas, la obra de Clarice Lispector está incrustada en la ciudad y en el tiempo presente, con un esfuerzo de objetivación de la realidad inmediata. Esto contribuyó para transformar su literatura en un fragmento de la vida urbana. Interioriza la acción, con una anécdota mínima. Un conflicto dramático se instala en la temática de la existencia, con su experiencia anterior (recuerdos, percepciones, apariencias huidizas). Registra la historia en su acaecer. Construye la novela bajo los ojos del lector, manipulando la inevitable ambigüedad de un presente, donde todo surge mezclado (sin la perspectiva seleccionada y esclarecedora de la distancia temporal) y donde los mismos acaecimientos cambian de substancia y de peso segun la luz que se haga incidir sobre ellos. ${ }^{2}$ Para la comprensión de la ficción contemporánea, es fundamental que se observe el desaparecimiento del punto fijo en que se 
colocaba el narrador, iluminando con su mirada segura las varias faces del mundo a ser revelado. E1 narrador-personaje, al mismo tiempo sujeto/objeto, no se suprime como narrador, sin llegar a una identificación total. Hay muchas voces, una comunicación entre conciencias, en un proceso fundamental de desdoblamiento. En esa estructura polifónica, el sujeto del enunciado se confunde con el sujeto de la enunciación, lo que abre al nivel de la significación una interpretación plurisignificativa y ambigua. Cuando es una tercera persona, ella se inmiscuye, creando el alejamiento máximo y tensión mínima entre enunciado y enunciación.

$\mathrm{Al}$ incorporar las contradicciones del mundo moderno a su creación, la artista realiza una obra abierta y dinámica, que se analiza para transformarse, que se cuestiona para captar el mundo y significarlo. La relación del arte con el mundo puede, así, ser percibida del ángulo irónico, contradictorio y polisémico, en la ambivalencia observador/observado. La introspección irónica se relaciona con el ángulo adoptado: distanciamiento del héroe (superando la distancia entre individuo y mundo, al perder el individuo la fe renacentista por la posición privilegiada de la conciencia humana delante del mundo). La presencia de lo real se da, así,en dimensión irónica, ya que su "realidad" se tiñe de irrealidad. El humor presta algo de maquinal a los gestos y actitudes para reducir lo patético y grave, la tensión de lo trágico a que la condición de "ser hombre" no consigue escapar. En esta percepción irónica del arte, según Muecke, ${ }^{3}$ se preservan las contradicciones a que está sujeta la "aventura de la escritura". ${ }^{4}$

En el espacio lúdico entre realidad y lenguaje, renunciando a toda referencia que no sea autorreferencia, en el mundo de los simulacros, el discurso toma la apariencia de un fantasma, como imagen de otro discurso (la enunciación en el enunciado, el no verbal en el verbal). La figura carnavalesca mascara y revela el texto mientras el texto mascara y de-vela el juego del signo. La búsqueda de la máscara o búsqueda del sentido remite a la experiencia de la literatura, incompleta y contradictoria, paradoxal. La ficción se mascara delante de lo referencial. La ilusión referencial del texto es que la imagen deriva de la palabra, el texto se presenta como condición de esa visibilidad y lectura. Fantasma y narrativa, como una misma práctica del signo, componen el discurso dialógico del texto. Denuncia/enunciado de los mitos del discurso social, subversión/transgresión de las prácticas literarias, pasando del deseo a la escritura, este mundo fundado en la ambigüedad es continua revisión de valores y certidumbres. En un discurso caracterizadamente dialógico, "la escritura se lee a sí misma y se construye en una génesis destruidora". ${ }^{5} \mathrm{El}$ deseo debe negarse para anunciarse, el corpus debe caracterizarse para aparecer.

\section{TECNICAS E ESTRUCTURA}

Una ordenación lógica preside el acto creador, al lado de un aspecto intuitivo. ${ }^{6}$ Los cuentos y novelas de Clarice Lispector son de estructura abierta, en infinitos diálogos con el lector que es llevado a juntar los índices, 
para recomponer la totalidad de lo real. Este es fragmentado con el intuito de dar una visión plurisignificativa.

Desde las primeras palabras, la $\mathrm{A}$. extiende los hilos de la acción que culmina en el desenlace. Unas veces hay un acercamiento lento al efecto culminante, otras la intensidad se manifiesta desde el comienzo (lo que no excluye un crecimiento progresivo del efecto).

La acción exterior es abolida en favor del momento que se arrastra y del sondeo psicológico de caracteres que se desintegran y de conciencias sorprendidas en el fluxo de ideas. En sus vueltas al pasado, las evocaciones no arrastran la nostalgia de un perdido ambiente natural sino comprueban la pérdida de una esencia, centro de una posible renovación dentro de la voraz vida urbana. La pérdida jamás podrá desaparecer, puesto que es la vida misma del hombre en su corporeidad. El fracaso corresponde a una frustrante existencia cuyas causas son psicoontológicas. No busca una explicación social, al nivel ideológico. Hay, por un momento, una conciencia lúcida del estado de frustración e imposibilidad de una vida plena. Ese vacío interior, ese sin sentido de la existencia, esa aguda soledad son constantes en la obra de Clarice Lispector. Hay, por lo tanto, temas que sobresalen sobre los demás y sus obras se presentan como sucesivas reelaboraciones de esos temas centrales. Esa tendencia reductora no se ejerce sobre los procedimientos estilísticos que se caracterizan cada vez más por un refinamiento de técnicas expresivas. Ese lenguaje que "solo se sumerge en la mitología personal y secreta del autor" (Barthes) es continuada lucha por expresarse y a su decifración libertadora. La constelación de imágenes es consecuencia de la actividad de lo imaginario que sobre ella imprime sus formas. La ficción pasa a ser una tesitura imagética. No se dirige a determinar la situación de ciertos seres sino la pura condición humana. A partir de hechos y personajes, en cualquier momento no previsto del tiempo, hace como un registro verbal de la realidad, que puede emparentarse con algunos mecanismos de la escritura automática de los surrealistas. Estos llevaron los autores contemporáneos a la conquista de la realidad en todos sus planos. A partir del surrealismo, y como valoración de las teorías de Freud y de las manifestaciones oníricas e ilógicas, puede decirse que sucedió en el terreno de las artes una aglutinación alrededor de lo fantástico en trayectoria opuesta a la razón, a lo organizadamente real. Dentro del surrealismo se realiza el punto alto de interpenetración de los varios tipos de arte: la confluencia ideal de la aplicación de procedimientos fotográficos, pictóricos, cinematográficos, todos ellos propios de la plasticidad surrealista. "El surrealismo, según MacAdam, 7 trataba de acumular en el mundo consciente los elementos de la subconciencia, acto que debería llevar al público a buscar dentro de sí, dentro de su propia subconciencia para descubrir el sector de su personalidad trivializado o destruído por una época materialista. En los cuentos de Clarice, como en sus novelas, hay un momento de autoexamen, provocado por un hecho externo, y luego estimulan una realización en el lector, mostrándole una 
imagen grotesca de sí mismo, una metáfora exagerada en términos de la realidad cotidiana. En su esfuerzo de modernización de la literatura, el surrealismo correspondía con el vitalismo de los escritores que emergían a la vida literaria. Representó una renovación de lo cotidiano, una espontaneidad creativa, un descubrimiento de lo insólito, de las energías operantes fuera de los cuadros convencionales de las sociedades.

\section{ANALISIS DEL CUENTO "AMOR"}

En su singular visión del mundo, el hombre, ente racional e intuitivo, persigue el conocimiento, a través de todo su ser. Utiliza los sentidos, lo que Clarice Lispector traduce en un lenguaje imagético y simbólico, que vamos a ver con más detenimiento en el análisis del cuento "Amor". El mergullo introspectivo se hace, la existencia imaginativa surge en un juego de espejos enfrentados donde se refleja la existencia material.

$\mathrm{El}$ análisis de formas cristalizadas de comportamiento tiene por objetivo desmitificar la sociedad, buscando anular o aniquilar los padrones y normas sociales ya consagrados, intentando hacer prevalecer lo individual sobre lo social. El narrador asume describir lo que se presenta: toma la posición de aquel que simplemente describe lo que enfoca, donde la verdad de la escritura es el ocultamiento de la mentira. Hay un proceso de alejamiento de lo que está siendo escrito en relación al contexto en que se insiere. Una visión directa entra en tensión con una distanciada:

"un poco cansada, con las compras deformando el nuevo saco de malla"(p.17).

El personaje aparece en una posición escénica, exteriorizada, cuya realidad interna es interpretada:

"se inquietaba...sentíase más sólida..." (p.18)

Poco a poco los actos se interiorizan. Pero algo de maquinal en los gestos y actitudes reduce lo patético y grave de la angustia existencial.

El discurso verbal cristalizado y socializado funciona como denunciador del proceso de revelación del mismo texto. Personaje y lector aceptan un mundo que no es su creación propia. El personaje es desmascarado por el enfoque crítico del narrador/autor. Para Ana, personaje del cuento, hay una incapacidad de percepción del mundo y su sentido. Repite mecánicamente las mismas acciones diarias y la continuidad del día-a-día las automatiza, hasta el desaparecimiento de la identidad individual. Su vida individual se vacía, hay una tensión, un doble movimiento individualidad/renuncia. Por la negación de sí misma, intenta alcanzar la propia realidad. El ciego que ve en una esquina va a representar el derrumbe del sistema, es el elemento desencadenador de la verdad y del cuestionamiento. El confronto con esos "deus ex machina", la cucaracha (en La pasión según G.H.) y con el ciego ("Amor") marca el inicio de una ruptura con el engrenaje, consumando un proceso subterráneo y fatal de desagregación. 
El personaje se desprende del mundo y experimenta la pérdida del yo: "los huevos se habían quebrado en el paquete de periódicos. Yemas amarillas y viscosas goteaban entre los hilos de la red"... "Varios años ruían, las yemas amarillas escurrían" (p. 21).

Ana empieza a experimentar el disgusto del mundo, la náusea, en el sentido sartriano. Por la repugnancia había salido de su mundo, por la repugnancia va a retornar a la normalidad de lo cotidiano. Hay una transgresión del sistema. Entre un antes y un después, las cosas cambian:

"La red de malla era áspera entre los dedos, no íntima cuando la había hecho. La red había perdido en sentido y estar en el tranvía era un hilo partido". (p. 21).

Todo que transcurre de la ruptura del sistema es consecuencia de una transgresión. ${ }^{9} \mathrm{El}$ vaciamiento de significado, primeramente en la pérdida de identificación personal y "glissement incessant du signifié sous le signifiant" 10 va de la "red", "yemas amarillas", pasando por "áspero", "íntimo". Al mismo tiempo, Ana se mueve por espacios limitados: tranvíacasa-jardín-casa, todos negadores de libertad.

El comportamiento artístico se caracteriza por el desdoblamiento del yo que se ve en el acto de producción, actor y espectador de sí mismo, sujeto del espectáculo y objeto del juego, captando una conciencia en fraccionamiento por la disociación del yo. El primado de la identidad define el mundo de la representación. Así se rompe la narrativa referencial por el diálogo entre el sujeto de la narración y el destinatario. En el espacio entre el escritor y el lector, el autor se estructura como significante y el texto como diálogo de varios discursos. El personaje permite la disyunción del sujeto de la narración en sujeto de la enunciación y sujeto del enunciado, éste como representante del sujeto de la enunciación y representado mientras objeto del sujeto de la enunciación. El yo es un otro que se manifiesta por una comunión con el mundo y aceptación existencial del objeto,una experiencia de la alteridad. El ciego la guía hasta él (p.24), su existencia es la existencia del otro. El cuestionamiento trae a la luz la contradicción entre realidad lírica y realidad empírica, como consecuencia del ilusionismo artístico que tiende a estimular la identificación entre ambos. El yo artístico se duplica en la imagen de un otro, que revela el yo como incompleto. En la estructura polifónica, el sujeto destinatario se representa en un discurso que es su propia contestación. La relación artista/obra es homóloga a la relación yo/mundo. En la estructura de la novela la polifónica, la escritura lee otra escritura, se lee a sí misma y se construye en una génesis destruidora.

Para hacer "aparecer un sentido secreto, la epifanía de un misterio", 11 Clarice Lispector busca el discurso interno del personaje en la imagen. Hay un sistema simbólico que habla en el espacio del texto, contribuyendo para una nueva dimensión ficcional. La imagen reduplica la narrativa por un 
proceso metonímico y su análisis demuestra que el lenguaje es el único que puede verticalizar el juego del hombre y de las cosas, en el proceso dialéctico de la realidad. El lenguaje, así comprendido, es el modo de ser de la realidad por la característica diseminada del objeto literario. El ciego, del cuento, es símbolo de mutilación. En las leyendas como en los sueños de la imaginación, el inconsciente es siempre representado bajo un aspecto tenebroso, bizco o ciego. Eros-Cupido tiene los ojos vendados. Edipo, la parte honda de la conciencia, se encarna en un personaje ciego. La red, es símbolo del devenir, de la continuidad; el hilo es una ligazón tranquilizadora. La cosa hilada es lo que se opone a la discontinuidad, a la ruptura. ${ }^{12}$ En el cuento "Amor", la red, que sostiene lo cotidiano se rompe, indicando un desorden bajo un orden aparente. En oposición a la raíz firme de los árboles que había plantado, pero que "cierta hora de la tarde se reían de ella"(p.13), hay "las raíces negras y suaves del mundo". El jardín donde Ana entra, simboliza las volupias secretas de la intimidad, el acercamiento a la verdad, puesto que el jardín primordial es el Paraíso. Los huevos están unidos al ritmo universal de renovación, al mismo tiempo que son símbolo de maturación e intimidad. Están dentro y después fuera de la red, han perdido su intimidad, pero Ana se entera de la verdad, comprende el proceso de maturación, al entrar en el mundo adulto. Al mismo tiempo en que penetrar en el acto vivo significa entrar en lo infernal:

"es que un mundo todo vivo tiene la fuerza de un Infierno" (p. 22, $L a$ pasión según G.H.).

La caminata de recuperación y descubrimiento- el ver-las experiencias y constataciones la hacen volver a lo cotidiano con otros ojos. Hay un nuevo modo de aprensión de la realidad. En esa relación nueva con las cosas, el detalle subraya la ilusión de realidad. La salida de la crisis implica en dolor. Ana vuelve a la vida silenciosa, lenta, insistente.

En el espacio de la narrativa, Ana se pierde y se busca, se reencuentra en el lenguaje de la obra. Por el lenguaje aprende la realidad última de las cosas:

"se peinaba sin ningún mundo en el corazón", mientras se aleja "del peligro de vivir" (p. 30). En el no-dicho encuentra su verdad.

\section{CONCLUSIONES}

Nuestro trabajo, desprovisto de cualquier intuito agotador, intentó caracterizar algunos procedimientos creadores de la obra de Clarice Lispector. A pesar de "work in progress", tiene hasta ahora tendencias que podemos considerar definidoras de su concepción del arte narrativo, de rara unidad y originalidad, donde bucea hacia el encuentro de una realidad última, perseguida en su contextura secreta con la objetividad de un microscopio. Ya lo dijo Barthes que, "para el verdadero escritor, escribir es hacer estremecer el sentido del mundo". La palabra poética es sobre todo transgresión pues depasa la lógica de lo codificado y establece, en el acto de 
escribir, la distancia entre deseo y universo. Clarice Lispector demuestra en su conciencia de ficcionista que la escena literaria es, por definición, ficcional, que su universo se construye en lo imaginario. Las frecuentes intrusiones del escritor deshacen la ilusión del arte. La nueva escritura rompe con el mundo referencial, asumiéndose como libertación, através de la destrucción de la escritura: el arte mata y resucita la realidad para hacerse significar.

Por las frecuentes reflexiones sobre la naturaleza de la creación artística, parte, con lucidez creadora, de las posibilidades del lenguaje, proponiendo una nueva escritura/lectura. La obra de Clarice Lispector, en su recusa de aceptar lo codificado, representa una transgresión y llega a una nueva visión del quehacer literario y un cuestionamiento de su significación. Universidade Federal do Rio de Janeiro

BELLA JOZEF

\section{NOTAS}

1. Las citas, traducidas por nosotros, corresponden a La pasión según G.H., Rio, Editora do Autor, 1964, p.19 y La vía crucis del cuerpo, Rio, Artenova, 1974, p.73.

2. JOZEF, BELLA.O espaço reconquistado, Petrópolis, Vozes, 1974, p. 16.

3. MUECKE. The Compass of Irony, London, Methuen, 1969, p.182.

4. RICARDOU, JEAN. Problemes do nouveau roman. Paris, Seuil, 1967, p.111.

5. KRISTEVA, JULIA. Introducão à semanálise, São Paulo, Perspectiva, 1974, p.76.

6. NUNES, BENEDITO. Clarice Lispector. São Paulo, Edições Quíron, 1973.

7. MAC ADAM, ALFRED. "Rayuela" de Julio Cortázar: un tipo de análisis estructural. $L a$ novela hispanoamericana actual, New York, Las Américas-Anaya, 1971, p.96.

8. LISPECTOR, CLARICE. La fos de Familia, Rio, José Olympio Edit., 1974, $6^{\mathrm{a}} \mathrm{ed}$.

9. NUNES, BENEDITO, idem, ibidem, p.63.

10. LACAN, J. Ecrits, Paris, Seuil, 1966, p.502.

11. DURAND, GILBERT. La imaginación simbólica, Buenos Aires, Amorrortu, 1971, p.15.

12. DURAND,GILBERT. Les structures anthropologiques de l'imaginaire. Paris, Bordas, 1969, pp.290, 371. 
